\title{
FOX FAECES AND VOLE DISTRIBUTION ON A LOCAL RANGE: ECOLOGICAL DATA IN A PARASITOLOGICAL PERSPECTIVE FOR ECHINOCOCCUS MULTILOCULARIS
}

\author{
GUISLAIN M.H.***, RAOUL F.*, POULLE M.L.****** \& GIRAUDOUX P.*
}

\section{Summary:}

The completion of the life cycle of Echinococcus multilocularis needs a spatial overlap between intermediate host species (voles) and definitive host (fox) faeces. Factors influencing the importance of this overlap were investigated in north eastern France.

Kilometric transects were walked to collect fox faeces and to estimate vole relative densities through surface indices. Habitat and climatic conditions were the strongest predictors of the number of faeces collected, while vole densities had no predictive power. Densities of both Microtus sp. and fox faeces were higher in medium-height vegetation edge. The consequences of such results to understand local transmission processes and human exposure are discussed.

KEY WORDS : Echinococcus multilocularis, Microtus, Arvicola terrestris, Vulpes vulpes, faeces, transmission, local range, habitat.
Résumé : DISTRIBUTION SPATIALE DES FÈCES DE RENARD ET DES CAMPAGNOLS : APPORTS DE DONNÉES ÉCOLOGIQUES À L'ÉTUDE DE LA TRANSMISSION D'ECHINOCOCCUS MULTILOCULARIS

La réalisation du cycle d'Echinococcus multilocularis nécessite la superposition spatiale entre ses hôtes intermédiaires (les campagnols Microtus arvalis et Arvicola terrestris) et les fèces de son hôte définitif (le renard, Vulpes vulpes). Les facteurs qui influencent cette superposition ont été étudiés dans le nord-est de la France par la réalisation de transects de collecte de fèces et d'estimation des densités de campagnols. Le type de milieu et les conditions climatiques sont les variables les plus explicatives de la distribution des fèces de renards, qui n'est pas fonction de celle des rongeurs. Cependant, les plus fortes densités en Microtus et fèces de renards ont été trouvées dans un même milieu : les lisières de végétation moyenne. L'importance de ces résultats pour la compréhension des processus locaux de transmission et du risque d'exposition humaine est discutée.

MOTS CLÉS : Echinococcus multilocularis, Microłus, Arvicola terrestris, Vulpes vulpes, fèces, transmission, échelle locale, milieu.

main definitive and intermediate hosts respectively. Average prevalence in small mammals intermediate hosts on a regional range is very low (about $0.1 \%$ ), but microfoci have been found in eastern France, with E. multilocularis prevalence rates locally exceeding $10 \%$ within a few $100 \mathrm{~m}^{2}$ (Delattre et al., 1988, 1990b; Giraudoux et al., 2002). Moreover, in Switzerland, prevalence in rodents can reach 10-39 \% in Arvicolidae (Gottstein et al., 1996, 2001; Hofer et al., 2000). Comparative studies in Europe have shown that E. multilocularis prevalence in foxes was dependent on landscape composition. Indeed, higher prevalence was recorded in landscapes favouring intermediate host population outbreaks (Pesson \& Carbiener, 1989; Raoul et al., 2001b; Staubach et al., 2001; Giraudoux et al., 2003).

Modifications in the population dynamics and in the spatio-temporal overlap of species involved in parasitic transmission can modulate zoonotic risk (Patz et al., 2004). Little is known about E. multilocularis transmission processes occurring on a local range (some square kilometres). Though transportation of E. multilocularis eggs by flies has been mentioned once in the literature (Rausch, 1995), one generally considers that the probability that a small mammal ingest a viable egg will partly depend upon the densities of eggs 
and of small mammal populations and upon the spatial overlap between them. As the Arvicolid and Microtine home range hardly exceeds 500 square meters (Spitz, 1977; Airoldi, 1978), E. multilocularis eggs have to be deposited via fox faeces within this range. Thus, the spatial proximity between intermediate hosts and definitive hosts faeces might be an important parameter controlling the "meeting filter" between hosts and parasite (Euzet \& Combes, 1980; Holmes, 1987; Combes, 2001). This is likely to be a function of fox defecating behaviour, as well as of fox and grassland rodent densities. At this range, rodent distribution among habitats has been described as very heterogeneous (Delattre et al., 1988; Butet \& Leroux, 1994; Giraudoux et al., 1994; Butet et al., 2006), and only one study indicated a heterogeneous distribution of fox faeces (Giraudoux et al., 2002). Furthermore, no data is available on the relationship between rodent and fox faeces distributions, despite its obvious interest in assessing the spatial variability of transmission.

Our objectives were to explore predictive factors of the spatial distribution of $E$. multilocularis intermediate hosts (A. terrestris and M. arvalis) and of faeces of E. multilocularis definitive host (red fox) on a very local range. We focused on ecological factors such as season, rainfall, temperature, habitat and rodent densities as potential predictive factors. This study is a first step in understanding the processes of parasite transmission on a local scale.

\section{MATERIALS AND METHODS}

\section{STUDY AREA}

T The study was conducted from March 2004 to October 2005 in a $90-\mathrm{km}^{2}$ rural area in the Ardennes, north-eastern France (N $49^{\circ} 28^{\prime}$ 57'; E $4^{\circ} 59^{\prime}$

$\left.28^{\prime \prime}\right)$. The first human case of alveolar echinococcosis was diagnosed in 1984 in this region (Depaquit et al., 1998), which is located at the western limit of the E. multilocularis European distribution (Giraudoux et al., 2001). Altitude ranges between 200 and 300 meters above sea level. The climate is continental with average temperatures lower than $6^{\circ} \mathrm{C}$ during five months of the year and regular precipitations all year long $(60 \mathrm{~mm}$ per month on the average). The study area includes arable land (28\%), grassland (32\%), and forest (35\%). The human population density is very low (eight inhabi$\operatorname{tants} / \mathrm{km}^{2}$ ) and distributed in very small discrete villages. Foxes are trapped and hunted the whole year round.

\section{FOX DENSITY ESTIMATION}

Minimum fox density was estimated by distance-sampling method, as described by Ruette et al. (2003). Ten spotlight counts were carried out yearly, from 2003 to 2006, during January and February, after fox dispersion and before its breeding season. A spotlight count consisted of a course of ten $1 \mathrm{~km}$-long sections. Surveys were carried out between 21:00 and 01:00 hours, except in case of heavy rain or fog. One driver and two observers were present for each count. The car speed was $10-15 \mathrm{~km} / \mathrm{h}$ and observers screened each side of the road with hand-held spotlights. For each observed fox, the perpendicular distance between the initial position of the fox (at first sight) and the road was measured using a laser telemeter. The densities of foxes were estimated from sighting data using the software DISTANCE 4.2 (Laake et al., 1993). Densities were estimated modelling their detection function, $\mathrm{g}(\mathrm{x})$, which is the probability in detecting a red fox that it is at distance $\mathrm{x}$ from the road. The analysis consisted of fitting the best model, grouping distance data (perpendicular distances between first sight of fox and the vehicle) into 60-m intervals and comparing different models. Akaïke's Information Criterion (AIC) was used to select the most appropriate model.

Densities were estimated according to the general equation $\mathrm{D}=\frac{\mathrm{n}}{2 . \mathrm{L} \cdot \mathrm{ESW}}$ (Buckland et al., 1993) where $\mathrm{n}$ is the number of sightings; $L$ the total transect length and ESW the effective strip width. The estimate of ESW was calculated from the estimated detection function obtained from models. A Chi-squared test was used to compare fox densities between years (Sauer \& Williams, 1989; Ruette et al., 2003).

\section{ESTIMATION OF VOLE AND FOX FAECES ABUNDANCES}

We estimated relative vole densities $(=$ abundance index) by an index method (Delattre et al., 1999; Quéré et al., 2000) usually employed for the large range estimation of small mammal relative density (Hansson, 1979; Delattre et al., 1999; Fichet-Calvet et al., 1999; Quéré et al., 2000). It is based on walked transects consisting of a succession of ten paces intervals, each of them measuring approximately 10 meters long. A band of two meters width was screened on each side of transects, to detect vole presence indices. Such methods have been calibrated against density estimates based on trapping (Delattre et al., 1990a; Quéré et al., 2000; Giraudoux et al., 1995). We concentrated on A. terrestris and $M$. arvalis because they are the main intermediate hosts of E. multilocularis in France (Rausch, 1995). M. arvalis is sympatric with Microtus agrestis in our study area, the latter at much lower density. Since both species can share the same habitat and cannot be distinguished by their presence indices, they were referred to as Microtus sp. We detected the presence of Microtus sp. through runways in vegetation and burrow entries, in association with 
fresh faeces and/or evidence of recent vegetation consumption (Delattre et al., 1990a) and the presence of $A$. terrestris through earth tumuli features (Giraudoux et al., 1995). Each 10 paces interval walked was considered "positive" or "negative" relative to the presence or the absence of A. terrestris and Microtus sp.

Furthermore, all carnivore faeces found on transects and identified as fox faeces on the basis of their odour and shape were collected and individually identified. Their geographical coordinates (Universal Transerve Mercator coordinate system) were recorded using Global Positioning System (GPS), as well as the habitat and the type of environmental features around them.

Walked transects were performed in five study sites, distant from each other by a minimum of $1.5 \mathrm{~km}$ and a maximum of $3.25 \mathrm{~km}$. At each site, transects were walked in eight different habitats: forest, arable land, pasture (presence of livestock for more than one month per year), meadow (presence of livestock for less than one month per year), lower-height vegetation edge (same height as neighbouring plots), medium-height vegetation edge (vegetation height from 0.5 meters to 2 meters), hedge (vegetation of more than 2 meters height, trees) and road and stream bank. Intervals walked in any other habitat than these eight ones were removed from the analyses ( $0.3 \%$ of the walked intervals). Since the visibility of fox faeces and burrow systems of rodents is dependent on the vegetation type and height, transects were walked from October to March, when the vegetation was at its lowest. From 2004 to 2005, transects were walked during winter months, before and after Arvicola and Microtus reproduction. Furthermore, an additional session was carried out in December 2004 to collect information about fox faeces distribution at the beginning of the fox mating period, which occurs between December and February (Cavallini \& Santini, 1996). The chi-square goodness-of-fit test (Siegel \& Castellan, 1988) was used to detect annual variations in the faeces Kilometric Abundance Index (KAI) by assessing the degree of correspondence between the observed and expected numbers of faeces found by winter. The excepted numbers of faeces found were calculated under the hypothesis that the number of faeces found during a given period is only dependent on the distance walked during this period. The 2003-2004 winter corresponds to the March 2004's transects; the 2004-2005 winter corresponds to the October 2004, December 2004 and March 2005's transects; the 2005-2006 winter corresponds to the October 2005's transect.

\section{STATISTICAL MODELLING}

Contiguous transect intervals walked during a given sampling period at a given site and in a given habitat were pooled, and constituted a sampling unit. Gene- ralized Linear Models (GLM) were used to test factors associated with: $i$ ) the number of intervals positive for Microtus sp. ("MICROTUS" response variable), ii) the number of intervals positive for A. terrestris ("ARVICOLA" response variable) and, iii) the number of fox faeces found ("FAECES" response variable). Models were computed using both Poisson link and negative binomial link functions, under the respective hypotheses of a random distribution and of an over-dispersion of rodents and faeces in habitats. Models were compared using the information theoretic method outlined by Burnham \& Anderson (2002), and presented according to Anderson et al. (2001). "INTERVALS" (number of intervals walked) was in first position in all models. We explored potential explanatory factors, which were thought to be relevant with regard to our study objectives: site, climate (rain and temperature), month, year, habitat, and densities of grassland rodents. Modelling the relative densities of MICROTUS and ARVICOLA, we first considered the effect of adding "SITE" (the study site where intervals were walked), as vole density can vary within a distance of a few kilometres (Delattre et al., 1999; Giraudoux et al., 1997). Then, we successively explored the effects of "RAIN" (cumulative rainfall during the month preceding transects), "TEMPERATURE" (mean temperature during the month preceding transect), "MONTH" (the month transect was walked: March, October or December) and "YEAR" (the year transect was walked: 2004 or 2005). Indeed, important rainfall is assumed to damage vole's runways, and favours their dispersion (Saucy \& Schneiter, 1997). Temperature can influence reproduction and mortality. The densities of Microtus sp. and A.terrestris might vary from March to October, due to reproduction cycle. Furthermore, vole densities vary from one year to another for both Microtus sp. (Delattre et al., 1999) and A. terrestris (Giraudoux et al., 1997). Because several studies have shown that densities of both Microtus sp. and A. terrestris varied according to habitat (Delattre et al., 1988; Butet \& Leroux, 1994; Giraudoux et al., 1994; Raoul et al., 2001a; Butet et al. 2006), our prior hypothesis concerning vole abundance considered that "HABITAT" (the type of habitat where the intervals were walked) was the most potential explanatory variable. So, this variable was placed at the end of the models, in order to check its effect, the other variables being controlled. We also explored the effect of ARVICOLA (after HABITAT) when modelling MICROTUS, and the effect of MICROTUS after HABITAT when modelling ARVICOLA, in order to assess a potential covariance between species (Giraudoux et al., 1994; Raoul et al., 2001a).

Modelling relative FAECES densities, we first considered the effect of adding "SITE" to assess heterogeneity in the spatial distribution at the range of the whole study area. Then, we checked the effect of 
MONTH, assuming that the fox faeces decomposition rate could differ from one season to another, as demonstrated for herbivores faeces (Nchanji \& Plumptre, 2001; Hemami \& Dolman, 2005). We also explored the effects of RAIN and TEMPERATURE because Cavallini (1994) reported that faeces life-span depended on rainfall over a period of 20 days before scats collection, and the effect of HABITAT, as it might influence E. multilocularis egg preservation or fox defecation behaviour. Our prior hypothesis concerning relative fox faeces density was that it depended on relative vole density. So we investigated the effects of MICROTUS and ARVICOLA on FAECES, after taking the effect of HABITAT into account, as we assumed the latter had a marked effect on relative vole densities. Since fox density estimation was undertaken in winter only, this variable has not been included as a predictive variable of fox faeces density. Analyses were realised using the R 2.2.1. (R Development Core Team, 2005) and the pgirmess 1.2.5. package for model selection (Giraudoux, 2006a).

\section{RESULTS}

$\Lambda$ total number of 19,479 intervals were walked, from which 1,393; 243 and 139 were positive for Microtus sp., A. terrestris and fox faeces respectively (Table I). From 669 to 834 intervals were walked by site and by session, and an average of $487 \pm$ 45 (SD) intervals were walked by habitat and by session. "Forest" was not sampled at site 5 because this habitat was absent there. "Meadow" was rare at sites 2 and 5; from 29 to 43 and from 57 to 108 intervals were walked by session in these two sites respectively.

A total of 145 red fox faeces were collected (135 intervals with only one fox drop, three intervals with two faeces and one interval with four faeces), among which $126(87 \%)$ were in edges ( 46 being collected in mediumheight vegetation edges). Ninety percent of the 145 faeces were found on non-conspicuous supports, such as earth, grass or moss. Only 14 faeces were found on more visible supports: cow dung (two faeces), stone (two faeces), scratched earth (two faeces) and mole hill (eight faeces). While the sampling effort remained relatively constant from one session to another, climate parameters varied, and the number of faeces collected by session decreased (Table I).

\section{FOX DENSITY AND FOX FAECES DENSITY}

The estimates of red fox densities varied from three foxes per $\mathrm{km}^{2}$ in winters of 2003-2004 and of 20042005, to four foxes per $\mathrm{km}^{2}$ in the winter of 2005-2006, however, fox densities did not vary significantly between winters $\left(\mathrm{Chi}^{2}=2.34, \mathrm{ddl}=2, \mathrm{p}=0.31\right)$. In contrast, the number of faeces found varied significantly between winters $\left(\mathrm{Chi}^{2}=47.38, \mathrm{df}=2, \mathrm{p}<0.001\right)$. Faeces KAI were of 1.51 faeces $/ \mathrm{km}$ in winter of 2003-2004 (39 km walked), 0.65 faeces $/ \mathrm{km}$ in winter of 2004-2005 (115.7 km walked) and 0.23 faeces $/ \mathrm{km}$ in winter of 2005-2006 (38.7 km walked).

\section{Determinants of MiCROTUS SP., A. TERRESTRIS AND FOX FAECES ABUNDANCE}

Modelling was based on a total of 919 sampling units. Fox faeces, $M$. arvalis and A. terrestris were present in 109, 432 and 91 units respectively. Table II shows the combination of variables that were examined for each response variable, the loglikehood and Akaike Information Criteria being those of the negative binomial error. Those for the Poisson error are not presented here. Indeed, differences of AIC or corrected AIC (AICc, if the number of observation is lesser than 40 times the number of explanatory variables) values between the best negative binomial model and the best Poisson model for the MICROTUS, ARVICOLA and FAECES response variables were of -770.8 (AICc), - 217.5 (AICc) and - 18.9 (AIC) respectively, which clearly favoured the choice of negative binomials models exclusively. This indicates that response variables were not randomly distributed but typically over-dispersed, as suggested by the dispersion parameter $\mathrm{q}$ ( \pm standard deviation) considering the best models: $\mathrm{q}=0.64 \pm 0.06$ for MICROTUS; $\mathrm{q}=0.20 \pm 0.04$ for ARVICOLA; $q=0.76 \pm 0.24$ for FAECES.

The relative abundance of Microtus sp. was best explained by the effects of MONTH and mean rainfall during

\begin{tabular}{|c|c|c|c|c|c|}
\hline & $\begin{array}{c}\text { March } \\
2004\end{array}$ & $\begin{array}{c}\text { October } \\
2004\end{array}$ & $\begin{array}{c}\text { December } \\
2004\end{array}$ & $\begin{array}{c}\text { March } \\
2005\end{array}$ & $\begin{array}{c}\text { October } \\
2005\end{array}$ \\
\hline Number of intervals walked & 3,963 & 3,918 & 3,868 & 3,855 & 3,875 \\
\hline Number of fox faeces collected & 60 & 29 & 25 & 24 & 9 \\
\hline Fox faeces kilometric abundance index & 1.51 & 0.75 & 0.62 & 0.60 & 0.23 \\
\hline Number of intervals positive for Microtus spp./100 intervals & 3.31 & 4.03 & 9.54 & 8.35 & 10.66 \\
\hline Number of intervals positive for $A$. terrestris/100 intervals & 1.36 & 0.97 & 0.18 & 1.12 & 2.61 \\
\hline Cumulative rainfall $(\mathrm{mm})$ during the previous month & 22.8 & 21.2 & 37.2 & 54.5 & 59.1 \\
\hline Mean temperature $\left({ }^{\circ} \mathrm{C}\right)$ during the previous month & 4.1 & 15.5 & 5.9 & 1.2 & 15.7 \\
\hline
\end{tabular}

Table I. - Number of intervals walked and of fox faeces collected, relative rodent densities, and cumulative rainfall and mean temperature the month before transects, according to sampling session. 


\begin{tabular}{|c|c|c|c|c|c|c|}
\hline (a) Models of Microtus spp. abundance & $\mathbf{L L}$ & $\mathbf{K}$ & $\mathbf{n} / \mathbf{K}$ & AICc & $\Delta_{\mathrm{i}}$ & $\mathbf{w}_{\mathbf{i}}$ \\
\hline INTERVALS & -1344.5 & 3 & 306.3 & $2,695.0$ & 289.5 & 0 \\
\hline INTERVALS + SITE & -1340.0 & 7 & 131.3 & $2,694.2$ & 288.7 & 0 \\
\hline INTERVALS + RAIN & -1329.2 & 4 & 229.8 & $2,666.3$ & 260.9 & 0 \\
\hline INTERVALS + RAIN + TEMPERATURE & -1328.7 & 5 & 183.8 & $2,667.4$ & 261.9 & 0 \\
\hline INTERVALS + RAIN + MONTH & -1322.5 & 6 & 153.2 & $2,657.2$ & 251.7 & 0 \\
\hline INTERVALS + RAIN + MONTH + HABITAT & -1195.3 & 13 & 70.7 & $2,417.1$ & 11.6 & 0 \\
\hline INTERVALS + RAIN + MONTH + HABITAT + ARVICOLA & -1195.3 & 14 & 65.6 & $2,419.1$ & 13.6 & 0 \\
\hline INTERVALS + RAIN + MONTH + HABITAT + MONTH:HABITAT & -1174.9 & 27 & 34.0 & $2,405.5$ & 0 & 1 \\
\hline (b) Models of Arvicola terrestris abundance & $\mathbf{L L}$ & $\mathbf{K}$ & $\mathbf{n} / \mathbf{K}$ & AICc & $\Delta_{\mathrm{i}}$ & $\mathbf{w}_{\mathbf{i}}$ \\
\hline INTERVALS & -450.8 & 3 & 306.3 & 907.6 & 75.6 & 0 \\
\hline INTERVALS + SITE & -437.3 & 7 & 131.3 & 888.7 & 56.7 & 0 \\
\hline INTERVALS + SITE + RAIN & -436.4 & 8 & 114.9 & 889.1 & 57.1 & 0 \\
\hline INTERVALS + SITE + TEMPERATURE & -435.8 & 8 & 114.9 & 887.7 & 55.7 & 0 \\
\hline INTERVALS + SITE + MONTH & -426.8 & 9 & 102.1 & 871.7 & 39.7 & 0 \\
\hline INTERVALS + SITE + MONTH + HABITAT & -400.8 & 16 & 57.4 & 834.1 & 2.14 & 0.23 \\
\hline INTERVALS + SITE + MONTH + HABITAT + MICROTUS & -400.7 & 17 & 54.1 & 836.0 & 4.0 & 0.09 \\
\hline INTERVALS + SITE + MONTH + HABITAT + MONTH:HABITAT & -385.0 & 30 & 30.6 & 832.0 & 0 & 0.68 \\
\hline (c) Models of fox faeces abundance & $\mathbf{L L}$ & $\mathbf{K}$ & $\mathbf{n} / \mathbf{K}$ & AICc & $\Delta_{\mathrm{i}}$ & $\mathbf{w}_{\mathbf{i}}$ \\
\hline INTERVALS & -409.8 & 3 & 306.3 & 825.6 & 74.6 & 0 \\
\hline INTERVALS + SITE & -401.6 & 7 & 131.3 & 817.2 & 66.2 & 0 \\
\hline INTERVALS + SITE + MONTH & -394.3 & 9 & 102.1 & 806.5 & 55.6 & 0 \\
\hline INTERVALS + SITE + MONTH + RAIN & -383.7 & 10 & 91.9 & 787.3 & 36.3 & 0 \\
\hline INTERVALS + SITE + MONTH + RAIN + TEMPERATURE & -383.6 & 11 & 83.5 & 789.3 & 38.3 & 0 \\
\hline INTERVALS + SITE + MONTH + RAIN + HABITAT & -358.5 & 17 & 54.1 & 751.0 & 0 & 0.42 \\
\hline INTERVALS + SITE + MONTH + RAIN + HABITAT + MICROTUS & -357.5 & 18 & 51.1 & 751.1 & 0.1 & 0.40 \\
\hline INTERVALS + SITE + MONTH + RAIN + HABITAT + ARVICOLA & -358.3 & 18 & 51.1 & 752.6 & 1.65 & 0.18 \\
\hline
\end{tabular}

$\mathrm{LL}=$ maximized log-likelihood; $\mathrm{K}=$ number of estimated parameters; $\mathrm{n} / \mathrm{K}=$ number of observations/K; AIC = first order Akaike information criterion; $\mathrm{AICC}=$ second order Akaike information criterion; $\Delta \mathrm{i}=$ difference between AIC and the lowest value of AIC or between AICc and the lowest value of AICc; wi $=$ Akaike weights. INTERVALS $=$ total number of intervals walked; SITE $=$ five study sites; RAIN = cumulative rainfall during the month preceding transects; TEMPERATURE $=$ mean temperature during the month preceding transect; $\mathrm{MONTH}=$ March, October or December; HABITAT = eight categories; MICROTUS = number of intervals with Microtus sp. indices; ARVICOLA = number of intervals with Arvicola terrestris indices. MONTH:HABITAT $=$ interactions between quoted variables. Bold caracters $=$ best AIC or AICc values.

Table II. - Comparison of negative binomial models for a Microtus sp.; b Arvicola terrestris; c fox faeces.

the preceding month, and an interaction term between MONTH and HABITAT (Table IIa). The relative abundance of $A$. terrestris was best explained by the effects of SITE, MONTH and HABITAT and an interaction term between MONTH and HABITAT (Table IIb). The relative abundance of fox faeces (Table IIc) was best explained by the effects of SITE, MONTH, RAIN and HABITAT.

\section{Distribution OF MICROTUS SP., A. TERRESTRIS AND FOX FAECES AMONG HABITATS}

Figure 1 shows the fitted values of each model selected. Higher relative Microtus sp. densities were generally observed in meadows, banks and medium-height vegetation edges, whatever the month, while lower relative densities were predicted in hedges, on arable land and in forests (Fig. 1a). Higher relative densities of A. terrestris were observed in meadows. Very low relative densities of this species were observed in banks, on arable land and in forests (Fig. 1b). The highest faeces KAI were observed in low and medium-height vegetation hedges, while intermediate levels were found in edges and banks. The lowest KAI were in pastures, meadows, forests and on arable land (Fig. 1c). On the whole, faeces KAI were higher in edges and lower in plots.

\section{DISCUSSION}

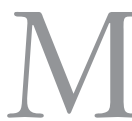
ost studies dealing with the ecology of E. multilocularis transmission have been conducted from continental to regional areas (Eckert \& Deplazes, 2004; Giraudoux et al., 2006b; Romig et al., 2006, for reviews). In contrast, only one study (Giraudoux et al., 2002) simultaneously addressed fox faeces and E. multilocularis intermediate host distributions on a very local range. Results presented here are therefore an original attempt to link fox faeces and rodent distributions taking into account ecological considerations, and a preliminary step to incorporate these data in a parasitological context.

The better fit of models using the negative binomial models indicated that fox faeces and intermediate hosts were typically over-dispersed. To our knowledge, this 

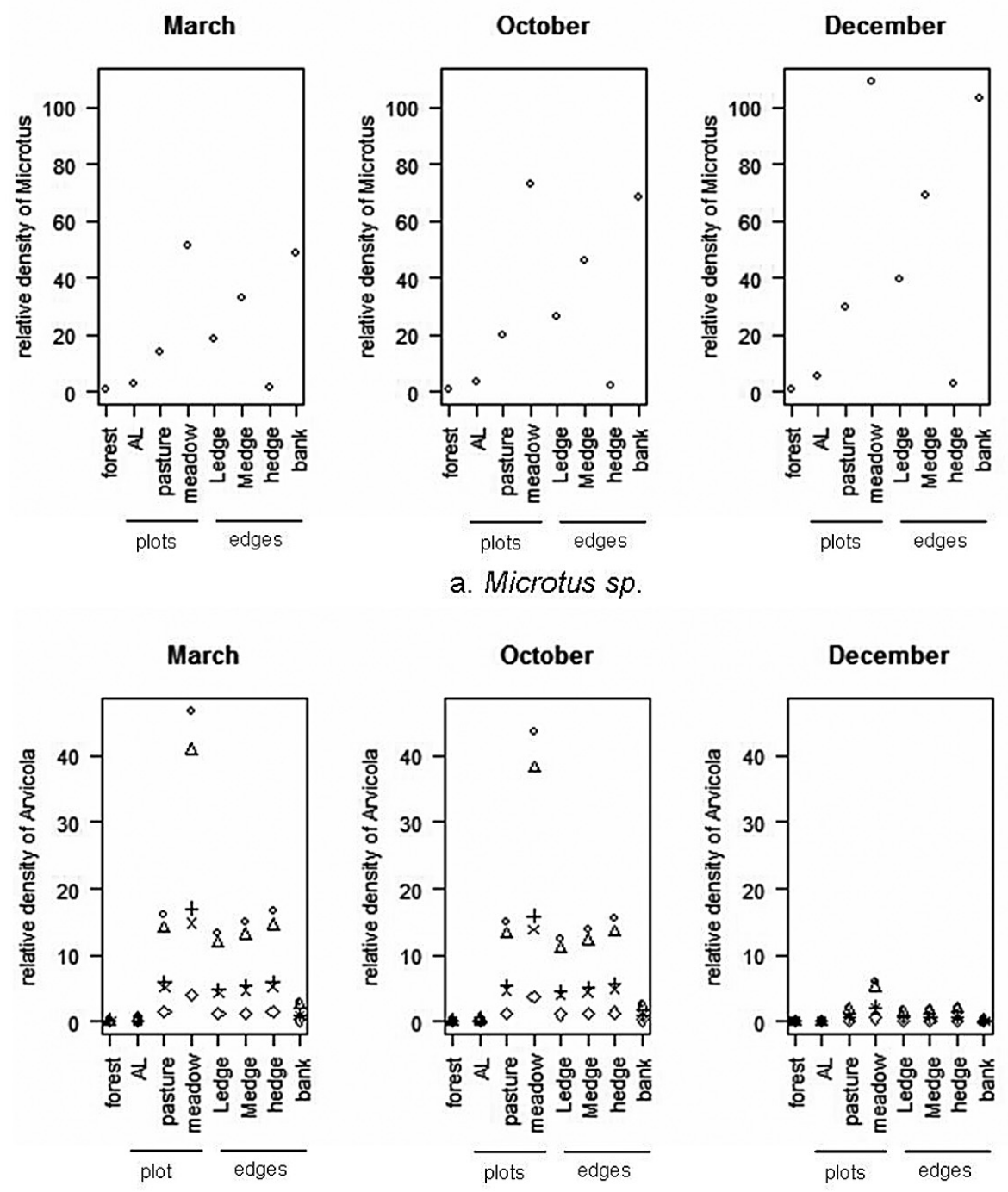

\section{b. Arvicola terrestris}
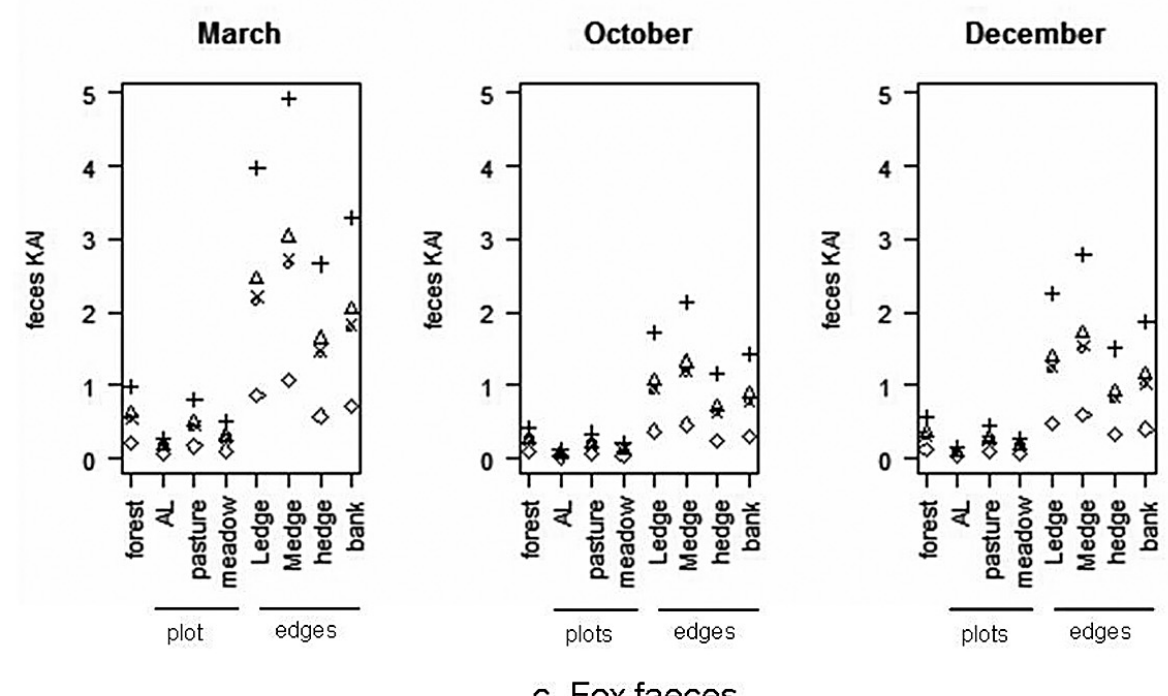

Fig. 1. - Predictions of the best models for relative densities of a Microtus sp. (number of positive intervals/100 intervals); b Arvicola terrestris (number of positive intervals/100 intervals); c fox faeces kilometric abundance index (KAI) (number of faeces found/100 intervals). $\mathrm{AL}=$ arable land; Ledge $=$ lower-height vegetation edge; Medge $=$ medium-height vegetation edge. Rainfall continuous variable was fixed to a constant value of $39 \mathrm{~mm}$ (mean value for the five sessions). 
is the first field evidence of the spatial clustering of both intermediate hosts and potentially contaminative material on a local range and on a fine grain. This may help to better understand processes leading to the spatial aggregative patterns of prevalence observed in definitive and intermediate E. multilocularis hosts (Raoul et al., 2001b; Staubach et al., 2001; Giraudoux et al., 2002; Hansen et al., 2004; Van der Giessen et al., 2004).

\section{VARIATIONS IN INTERMEDIATE HOST DENSITIES}

The abundance index of Microtus sp. did not exceed $11 \%$ over the study period, which is far from $80 \%$ recorded in the Jura Mountains during population outbreaks in landscapes dominated by grassland (Giraudoux et al., 1997; Delattre et al., 1999). In the same way, the relative densities of $A$. terrestris were of a few percents. Thus, in our study area almost equally composed of arable land, grassland, and forests, both Microtus sp. and A. terrestris densities appeared to be much lower than in landscapes dominated by grassland. In accordance with most studies on vole population dynamics, the relative abundance of these two species appeared to be seasonal, which is reflected by the variable MONTH in model. Seasonal densities in small rodents are classically linked to reproduction, mortality, movements, etc. Controlling for seasons, our study showed higher relative densities of Microtus sp. in meadows and in banks and medium-height vegetation edges and lowest relative densities in forests and on arable land. Those variations among habitats are in accordance with the high level of heterogeneity of Microtus sp. within the habitats already described (Butet \& Leroux, 1994; Giraudoux et al., 1994; Delattre et al., 1996; Butet et al., 2006).

\section{VARIATIONS IN FOX FAECES DENSITY}

Density of faeces varied according to months, which could be expected to be linked to seasonal fluctuations in fox population. Assuming this, we should find a minimum number of faeces in March, when population is at its lowest level. Our data do not support this hypothesis. They are in accordance with Cavallini (1994), who noticed that the faeces index was not related to the seasonal fluctuations in fox numbers, as it neither increased following spring reproduction, nor decreased during the fox hunting season. Cavallini (1994) rather suggests that the number of faeces found in the field is linked to faeces persistence time. This can vary according to season for elephant (Nchanji \& Plumptre, 2001) and to season, habitat and climatic conditions for cervids (Hemami \& Dolman, 2005). Furthermore, William \& Warren (2004) indicated that the action of invertebrates can diminish persistence time of sheep faeces. A few studies also showed a decrease in carnivore faeces persistence time in relation with removal by small mammals (Sanchez et al., 2004) or with rain- fall (Cavallini, 1994). The number of faeces we found was significantly related to rainfall: the number of faeces decreased by a factor six during the study period with a concomitant increase of rainfall. This supports the hypothesis that increased rainfall may have decreased faeces persistence time.

In accordance with Goszczynski (1990), we observed that the majority of faeces were simply left on nonconspicuous supports. This supports the results of Asa et al. (1985), Asa (1993) and Gese \& Ruff (1997) arguing that canids use mainly urine instead of faeces for scentmarking. Our results showed the heterogeneity of fox faeces distribution among sites and among habitats. This suggests a complex pattern of spatial fox faeces distribution in the whole study area and among habitats within sites. To our knowledge, there is a lack of studies on faeces distribution according to habitats at a fine grain. Webbon et al. (2004) recorded no differences in the number of fox faeces found among sites classified as arable, pastoral or mixed. Giraudoux et al. (2002) compared fox faeces densities among habitats on a smaller spatial range. They sought for faeces in ploughed field borders, road verges and other habitats (mainly grasslands) and found a significantly higher density of fox faeces both on the borders of ploughed fields and on road verges. Our results come to confirm those results since the highest densities of faeces were in edge habitats. No significant linear correlation between fox faeces and small mammal densities was found. A potential confounding effect of the variable habitat can be suspected.

\section{HABITATS AND PARASITE TRANSMISSION}

Echinococcus multilocularis was detected in only six faeces (ELISA copro-test confirmed by PCR and DNA sequencing, five of them in edges, data not shown), precluding any attempt of modeling parasite data straightfully. However, assuming that parasite distribution is a function of faeces density, the observed variations in the relative abundance of both faeces and voles between habitats suggested different levels of parasite transmission from contaminated faeces to rodents, depending on the micro-habitats (Table III). In habitats such as arable land and forest, since both relative abundances of fox faeces and rodents were low, the transmission of E. multilocularis eggs from contaminated faeces to the intermediate host was unlikely to occur. In contrast, in habitats such as medium-height vegetation edge and bank, both high fox faeces and intermediate host densities were recorded. This suggests a higher opening degree of the meeting filter in this habitat, e.g. a higher estimated meeting risk. Between these two situations, in the other habitats density of fox faeces could vary differently from those of voles, each density acting positively or negatively on the estimated meeting risk, which may result in intermediate levels of transmission intensity, i.e. 


\begin{tabular}{|c|c|c|c|}
\hline Habitats & $\begin{array}{l}\text { Faeces } \\
\text { relative density }\end{array}$ & $\begin{array}{l}\text { Intermediate host } \\
\text { relative density }\end{array}$ & $\begin{array}{l}\text { Estimated } \\
\text { meeting risk }\end{array}$ \\
\hline $\begin{array}{r}\text { Arable land } \\
\text { Forest }\end{array}$ & + & + & Low \\
\hline Pasture & + & ++ & Low to medium \\
\hline Meadow & + & +++ & Medium \\
\hline Hedge & +++ & + & Medium \\
\hline Lower-height vegetation edge & +++ & ++ & Medium to high \\
\hline $\begin{array}{r}\text { Medium-height vegetation edge } \\
\text { Bank }\end{array}$ & +++ & +++ & High \\
\hline
\end{tabular}

Table III. - Influence of faeces and intermediate host relative densities on the estimated meeting risk. + , low relative density;,++ medium relative density; +++ , high relative density.

in hedge. Because it is known that elevated temperature and desiccation can effectively reduce eggs infectivity (Veit et al., 1995), microclimate factors linked with habitat should be taken into account (Hansen et al., 2004). On the one hand, high vegetation in mediumheight vegetation edges and hedges may dampen the effects of hot temperatures and desiccation in summer, allowing a better egg survival. On the other hand, mechanical actions (ploughing, grazing, etc.) in plots could offer good conditions for eggs preservation by burying them in the soil (Delattre et al., 1988, 1990b). Medium-height vegetation edges may therefore be a key habitat for E. multilocularis transmission because both intermediate hosts and faeces of definitive hosts are present in high density, possibly in association with more favourable conditions for egg preservation. However, the effect of micro-local environmental conditions linked to habitat on egg preservation still needs to be addressed for proper estimation of transmission risks. Finally, human exposure may additionally depend on local habits (e.g. dandelions and mushrooms are by far more collected in grassland than in edges).

\section{CONCLUSION}

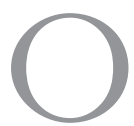

ur study provides original data on the spatiotemporal overlapping patterns between intermediate hosts and definitive host faeces on a fine grain. At a grain of some square meters, environmental conditions may change greatly regarding intermediate host and faeces densities as well as habitat conditions that may affect egg survival. This result is of primary importance to understand local E. multilocularis transmission patterns. Those aspects should then i) pave the road to studies targeted toward transmission processes on a local range, and ii) be better quantified in various landscapes in order to understand which focal habitats may present a greater risk for transmission and may be a possible target for prevention control.

\section{ACKNOWLEDGEMENTS}

$\mathrm{F}$ inancial and logistic support for this study was provided by the French "Direction Régionale à la Recherche et à la Technologie", the "Conseil Régional Champagne-Ardenne", the "Communauté de Communes de l'Argonne Ardennaise" and the "Programme pluriformation Milieux Naturels - Milieux anthropisés, University of Franche-Comté".

\section{REFERENCES}

AIROLDI J.P. Étude par capture et recapture d'une population de Campagnols terrestres Arvicola terrestris scherman Shaw. Terre et Vie, 1978, 32, 3-45.

Anderson D.R., Link W.A., Johnson D.H. \& Burnham K.P. Suggestions for presenting the results of data analyses. Journal of Wildlife Management, 2001, 65, 373-378.

Asa C.S., Peterson E.K., Seal U.S. \& Mech L.D. Deposition of anal-sac secretions by captive wolves (Canis lupus). Journal of Mammalogy, 1985, 66, 89-93.

Asa C.S. Relative contributions of urine and anal-sac secretions in scent marks of large felids. American Zoologist, 1993, 33, 167-172. 
Buckland S.T., Anderson D.R., Burnham K.P. \& LaAke J.L. Distance sampling. Estimating abundance of biological populations. Chapman \& Hall, London, UK, 1993.

Burnham K.P. \& Anderson D.R. Model selection and multimodel inference: a practical information-theoretic approach. Springer Editions, 2002.

Butet A. \& Leroux A. Spatial and temporal density fluctuations in commom vole populations in a marsh in western France. Polish Ecology Study, 1994, 20, 137-146.

Butet A., Paillat G. \& Delettre Y. Factors driving small rodents assemblages from field boundaries in agricultural landscapes of western France. Landscape Ecology, 2006, 21, 449-461.

Cavaluini P. Faeces count as an index of fox abundance. Acta Theriologica, 1994, 39, 417-424.

Cavaluini P. \& Santini S. Reproduction of the red fox Vulpes vulpes in Central Italy. Annales Zoologici Fennici, 1996, 33, 267-274

Combes C. Les associations du vivant. L'art d'être parasite. Flammarion, Paris, 2001.

Delattre P., Pascal M., Le Pesteur M.H., Giraudoux P. \& Damange J.P. Caractéristiques écologiques et épidémiologiques de l'Echinococcus multilocularis au cours d'un cycle complet des populations d'un hôte intermédiaire (Microtus arvalis). Canadian Journal of Zoology, 1988, 66, 2740-2750.

Delattre P., Giraudoux P., Damange J.P. \& Quéré J.P. Recherche d'un indicateur de la cinétique démographique des populations du campagnol des champs (Microtus arvalis). Terre et Vie, 1990a, 45, 375-384.

Delattre P., Giraudoux P. \& Quéré J.P. Conséquence épidémiologique de la réceptivité d'un nouvel hôte intermédiaire du ténia multiloculaire (Echinococcus multilocularis) et de la localisation spatiotemporelle des rongeurs infestés. Comptes Rendus de l'Académie des Sciences Paris, 1990b, 310, 339-344.

Delattre P., Giraudoux P., Baudry J., Quéré J.P. \& Fichet E. Effect of landscape structure on Common Vole (Microtus arvalis) distribution and abundance at several space scales. Landscape Ecology, 1996, 11, 279-288.

Delattre P., De Sousa B., Fichet-Calvet E., Quéré J.P. \& GirauDoux P. Vole outbreaks in a landscape context: evidence from a six-year study of Microtus arvalis. Landscape Ecology, 1999, 14, 401-412.

Depaquit J., Gallego A., Usseglio F., Liance M. \& Favriel J.M. L'échinococcose alvéolaire dans le département français des Ardennes : cas isolés ou nouveau foyer? Parasite, 1998, 5, 285-287.

Eckert J., Rausch R.L., Gemmell M.A., Giraudoux P., Kamiya M., Liu F.J., Schantz P.M. \& Romig T. Epidemiology of Echinococcus multilocularis, Echinococcus vogeli and Echinococcus oligarthus, in: WHO/OIE Manual on Echinococcosis in Humans and Animals: A public health problem of global concern. Eckert J., Gemmell M.A., Meslin F.X. \& Pawlowski Z.S. (eds), OIE/WHO, Paris, 2001, 164-182.

ECKert J. \& Deplazes P. Biological, epidemiological, and clinical aspects of echinococcosis, a zoonosis of increasing concern. Clinical Microbiology Revue, 2004, 17, 107-135.
Euzet L. \& Combes B. Les problèmes de l'espèce chez les animaux parasites. Mémoires de la Société Zoologique de France, 1980, 40, 239-285.

Fichet-Calvet E., Jomaa I., Giraudoux P. \& Ashford W. Estimation of sand rat abundance by using surface indices. Acta Theriologica, 1999, 44, 353-362.

GESE E.M. \& RuFf R.L. Scent-marking by coyotes, Canis latrans: the influence of social and ecological factors. Animal Behaviour, 1997, 54, 1155-1166.

Giraudoux P., Delattre P., Quéré J.P. \& Damange J.P. Structure and kinetics of rodent populations, in a region under agricultural land abandonment. Acta Oecologica, 1994, 15, 385-400.

Giraudoux P., Pradier B., Delattre P., Deblay S., Salvi D. \& Defaut R. Estimation of water vole abundance by using surface indices. Acta Theriologica, 1995, 40, 77-96.

Giraudoux P., Delattre P., Habert M., Quéré J.P., Deblay S., Defaut R., Duhamel R., Moissenet M.F., Salvi D. \& TrucheTET D. Population dynamics of fossorial water vole (Arvicola terrestris scherman): a land use and landscape perspective. Agriculture, Ecosystems and Environement, 1997, 66, 47-60.

Giraudoux P., Raoul F., Bardonnet K., Vuillaume P., Tourneux F., Cliquet F., Delattre P. \& Vuitton D.A. Alveolar echinococcosis: characteristics of a possible emergence and new perspectives in epidemiosurveillance. Médecine et Maladies Infectieuses, 2001, 31, 247-256.

Giraudoux P., Delattre P., Takahashi K., Raoul F., Quéré J.P., Craig P. \& Vutton D., in: Transmission ecology of Echinococcus multilocularis in wildlife: what can be learned from comparative studies and multiscale approaches? Craig P. \& Pawlowski Z. (eds), Cestode Zoonoses: Echinococcosis and Cysticercosis, IOS Press, 2002, 251-266.

Giraudoux P., Craig P.S., Delattre P., Bao G., Bartholomot B., Harraga S., Quéré J.P., Raoul F., Wang Y., Shi D. \& VuitTon D.A. Interactions between landscape changes and host communities can regulate Echinococcus multilocularis transmission. Parasitology, 2003, 127, S1-S11.

GIRAUDOUX P. pgirmess: miscellaneous functions for analysis and display of ecological and spatial data. $\mathrm{R}$ package version 1.2.5, 2006a, http://lbe.univ-fcomte.fr/telechar/

Giraudoux P., Pleydell D., Raoul F., Quéré J.P., Wang Q., Yang Y., VuitTon D.A., Qiu J., Yang W. \& Craig P.S. Transmission ecology of Echinococcus multilocularis: what are the ranges of parasite stability among various host communities in China? Parasitology International, 2006b, 55, S237-S246.

Goszczynski J. Scent marking by red foxes in Central Poland during the winter season. Acta Theriologica, 1990, 35, 7-16.

Gottstein B., Saucy F., Wyss C., Siegenthaler M., Jacquier P., Schmitt M., Brossard M. \& Demierre G. Investigations on a swiss area highly endemic for Echinococcus multilocularis. Applied Parasitology, 1996, 37, 129-136.

Gottstein B., Saucy F., Deplazes P., Reichen J., Demierre G., Busato A., Zuercher C. \& Pugin P. Is high prevalence of Echinococcus multilocularis in wild and domestic animals associated with disease incidence in humans? Emerging Infectious Diseases, 2001, 7, 408-412. 
Hansen F., Jeltsch F., Tackman K., Staubach C. \& Thulke H.H. Processes leading to a spatial aggregation of Echinococcus multilocularis in its natural intermediate host Microtus arvalis. International Journal for Parasitology, 2004, 34, $37-44$.

HANSSON L. Field signs as indicators of vole abundance. Journal of Applied Ecology, 1979, 16, 339-347.

Hemami M.R., Dolman P.M. The disappearance of muntjac (Muntiacus reevesi) and roe deer (Capreolus capreolus) pellet groups in a pine forest of lowland England. European Journal of Wildlife Research, 2005, 51, 19-24.

Hofer S., Gloor S., Muller U., Mathis A., Hegglin D. \& DeplaZES P. High prevalence of Echinococcus multilocularis in urban red foxes (Vulpes vulpes) and voles (Arvicola terrestris) in the city of Zurïch, Switzerland. Parasitology, 2000, 120, 135-142.

Holmes J.C. The structure of helminth communities. International Journal for Parasitology, 1987, 17, 203-208.

Kern P., Bardonnet K., Renner E., Auer H., Pawlowski Z., Ammann R.W., Vuitton D.A., Kern P. \& the European EchINOCOCCOSIS RegISTRY. European Echinococcosis Registry: human alveolar echinococcosis, Europe, 1982-2000. Emerging Infectious Diseases, 2003, 9, 343-349.

LaAke J.L., Buckland S.T., Anderson D.R. \& Burnham K.P. DiSTANCE User's guide. Colorado cooperative fish and wildlife research unit. Colorado State University, Fort Collins, CO, 1993.

NChAnjI A.C. \& Plumtre A.J. Seasonality in elephant dung decay and implications for censuring and population monitoring in southwerstern Cameroon. African Journal of Ecology, 2001, 39, 24-32.

Pesson B. \& CARBIENER R. Écologie de l'échinococcose alvéolaire en Alsace : le parasitisme du renard roux (Vulpes vulpes L.). Bulletin d'Écologie, 1989, 20, 295-301.

Quéré J.P., Raoul F., Giraudoux P. \& Delattre P. An index method of estimating relative population densities of the common vole (Microtus arvalis) at landscape scale. Terre et Vie, 2000, 55, 25-31.

Raoul F., Defaut R., Michelat D., Montadert M., Pépin D., Quéré J.P., Tissot B., Delattre P. \& Giraudoux P. Landscape effects on the population dynamics of small mammal communities: a preliminary analysis of prey-resource variations. Terre et Vie, 2001a, 56, 339-351.

Raoul F., Nonaka N., Piarroux R., Vuttton D.A. \& Giraudoux P. Assessment of the epidemiological status of Echinococcus multilocularis in foxes in France using ELISA coprotests on fox faeces collected in the field. International Journal for Parasitology, 2001b, 31, 1579-1588.

RAUSCH R.L. Life-cycle patterns and geographic distribution of Echinococcus species, in: Echinococcus and hydatid disease. Thomson R.C.A. \& Lymbery A.J. (eds), CAB International, Wallingford, 1995, 88-134.

Romig T., Dinkel A. \& Mackenstedt U. The present situation of echinococcosis in Europe. Parasitology International, 2006, 55, S187-S191.

Ruette S., Sthal P. \& Albaret M. Applying distance-sampling methods to spotlight counts of red foxes. Journal of Applied Ecology, 2003, 40, 32-43.
Sanchez D.M., Krausman P.R., Livingston T.R. \& Gipson P.S. Persistence of carnivore scat in the Sonoran Desert. Wildlife Society Bulletin, 2004, 32, 366-372.

SAucy F. \& SchneIter B. Juvenile dispersal in the vole Arvicola terrestris during rainy nights: a preliminary report. Bulletin de la Société Vaudoise de Sciences Naturelles, 1997, 84, 333-345.

SAUER J.R. \& Williams B.K. Generalized procedures for testing hypotheses about survival or recovery rates. Journal of Wildlife Management, 1989, 53, 137-142.

Siegel S. \& Castellan N.J.J. Non parametric statistics for the behavioural sciences. McGraw-Hill International Editions, New York, 1988.

SPITz F. Le campagnol des champs (Microtus arvalis (Pallas)) en Europe. Bulletin OEPP, 1977, 7, 165-175.

Staubach C., Thulke H.H., Tackmann K., Hugh-Jones M. \& ConRaths F.J. Geographic information system-aided analysis of factors associated with the spatial distribution of Echinococcus multilocularis infections of foxes. American Journal of Medicine and Hygiene, 2001, 65, 943-948.

Thompson R.C.A. \& MacManus D.P. Aetiology: parasites and life-cycles, in: WHO/OIE Manual on echinococcosis in humans and animals: A public health problem of global concern. Eckert J., Gemmell M.A., Meslin F.X. \& Pawlowski Z.S. (eds), OIE/WHO, Paris, 2001, 1-19.

Van Der Giessen J.B.W., Rombout Y. \& Teunis P. Base line prevalence and spatial distribution of Echinococcus multilocularis in a newly recognized endemic area in the Netherlands. Veterinary Parasitology, 2004, 119, 27-35.

Veit P., Bilger B., Schad V., SchäFer J., Frank W. \& Lucius R. Influence of environmental factors on the infectivity of Echinococcus multilocularis eggs. Parasitology, 1995, 110, 79-86.

Webbon C.C., Baker P.J. \& Harris S. Faecal density counts for monitoring changes in red fox numbers in rural Britain. Journal of Applied Ecology, 2004, 41, 768-779.

Williams B. \& WARREN J. Effects of spatial distribution on the decomposition of sheep faeces in different vegetation types. Agriculture, Ecosystems and Environment, 2004, 103, 237-243.

Reçu le 19 février 2007 Accepté le 8 octobre 2007 